\title{
Are reactions between allylpotassiums and halotrimethylsilanes diffusion-controlled?
}

\author{
Eric Masson* ${ }^{\mathrm{a}}$ and (the late) Manfred Schlosser ${ }^{\mathrm{b}}$ \\ ${ }^{a}$ Department of Chemistry and Biochemistry, Ohio University, Athens, Ohio 45701, USA \\ ${ }^{b}$ Institute of Chemical Sciences and Engineering, Ecole Polytechnique Fédérale, \\ 1015 Lausanne, Switzerland \\ E-mail:masson@ohio.edu
}

Dedicated to Professor Manfred Schlosser in honor of his scientific achievements

DOI: http://dx.doi.org/10.3998/ark.5550190.p009.019

\begin{abstract}
The order of reactivity $(\mathrm{X}=\mathrm{F}<\mathrm{Cl}<\mathrm{Br}<\mathrm{I})$ determined for the reaction of the model nucleophile pinenylpotassium with halotrimethylsilanes $\mathrm{XSi}\left(\mathrm{CH}_{3}\right)_{3}$ in hexane and with halotriisopropylsilanes $\mathrm{XSi}\left({ }^{i} \mathrm{C}_{3} \mathrm{H}_{7}\right)_{3}$ in tetrahydrofuran supports a single-step $\mathrm{S}_{\mathrm{N}} 2(\mathrm{Si})$ mechanism over the formation of a pentavalent intermediate. However, no leaving group effect is found $(\mathrm{X}=$ $\mathrm{F} \approx \mathrm{Cl} \approx \mathrm{Br} \approx \mathrm{I}$ ) when the condensation of pinenylpotassium with halotrimethylsilanes is accomplished in tetrahydrofuran. Under such conditions the crucial event appears to be diffusion-controlled precomplex formation followed by rapid metal halide ejection.
\end{abstract}

Keywords: Allylmetals, silanes, nucleophilic substitution, kinetics, diffusion control

\section{Introduction}

$\mathrm{S}_{\mathrm{N}} 2$ nucleophilic substitutions are among the first reaction pathways taught in an organic chemistry course. Their most fascinating characteristics, such as the simultaneity ("concertedness") of bond-breaking and bond-making, can be probed in various ways by assessing leaving group effects on reaction rates and geometry changes, such as the Walden inversion of configuration at the exchange site.

Crowding at the reaction center compromises the $\mathrm{S}_{\mathrm{N}} 2$ process. Secondary alkyl halides undergo substitution far more slowly than primary ones, let alone methyl halides, and we found only one case of unequivocal intermolecular nucleophilic displacement at a trialkyl-substituted carbon center $^{1}$ (substrates rather undergo $\beta$-elimination when attacked by an electron-rich species). In contrast, tertiary silyl halides can be subjected to nucleophilic substitution without 
any problem. The intriguing question is whether they employ the same $\mathrm{S}_{\mathrm{N}} 2$ mode as the unbranched carba-analogs do. Although there are good reasons to assume this in at least a few typical cases, ${ }^{2,3}$ addition-elimination sequences featuring a siliconate complex as the key intermediate are generally favored. ${ }^{4-6}$ The involvement of positively charged silenium ions can be ruled out in apolar media ${ }^{7}$ and perhaps even under solvolytic conditions. ${ }^{8}$

The stereochemical course of the substitution occurring at silicon is not a very instructive criterion as inversion or retention of configuration is highly dependent on the nature of the substrate, leaving group, nucleophile and solvent. ${ }^{9-14}$ Therefore, we hoped to gain new insight into the mechanism by determining the so far neglected effect of leaving groups on the substitution rates. To this end, we have carried out competition experiments using pinenylpotassium ${ }^{15}$ as nucleophilic reagent and a series of halotrialkylsilanes $\mathrm{XSiR}_{3}(\mathrm{X}=\mathrm{F}, \mathrm{Cl}$, $\left.\mathrm{Br}, \mathrm{I} ; \mathrm{R}=\mathrm{Me},{ }^{i} \mathrm{Pr}\right)$. Pinenylpotassium could be obtained almost quantitatively by treating $(-)-\beta-$ pinene with an equimolar mixture of butyllithium and potassium tert-butoxide, hence the choice of this nucleophile. Halotrialkylsilanes then react exclusively at the terminal $\alpha$-position of the allylic unit (see Scheme 1).
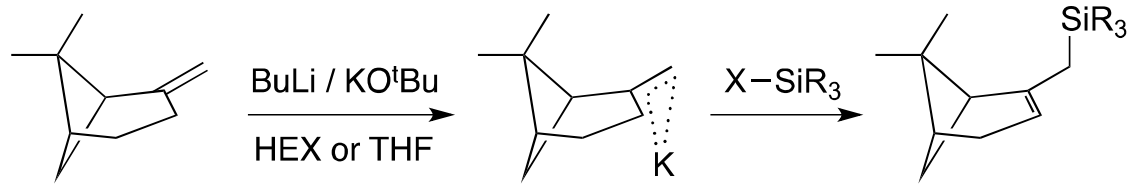

1a: $\mathrm{R}=\mathrm{CH}_{3}$
1b: $\mathrm{R}=\mathrm{C}_{2} \mathrm{H}_{5}$
1c: $\mathrm{R}={ }^{i} \mathrm{C}_{3} \mathrm{H}_{7}$

Scheme 1. Metalation of (-)- $\beta$-pinene and electrophilic interception with halotrialkylsilanes.

\section{Results and Discussion}

The reactions produced significantly different results depending on the medium in which they were performed. In hexane suspension, chlorotrimethylsilane reacted with pinenylpotassium six times faster than its fluoro analog and approximately three and four times more slowly than the bromo and iodo derivatives, respectively (see Table 1). When chlorotrimethylsilane was replaced by chlorotriethylsilane, the rate dropped by a factor of 19 . However, in tetrahydrofuran solution, fluoro-, chloro- and bromotrimethylsilane exhibited strictly the same reactivity and only iodotrimethylsilane lagged a little behind. Also, chlorotriethylsilane reacted only 1.1 times more slowly than chlorotrimethylsilane (Table 1). The increase in reactivity along the halogen series observed with halotrimethylsilanes in hexane was observed again in tetrahydrofuran with halotriisopropylsilanes. Fluorotriisopropylsilane was found to combine with pinenylpotassium four times more slowly than chlorotriisopropylsilane, whereas the bromo and iodo analogs reacted approximately twice as fast (see Table 1).

The leaving group effect observed in hexane with halotrimethylsilanes (with rates varying by up to 25-fold) and in tetrahydrofuran with halotriisopropylsilanes (up to 8-fold rate increases along the halogen series) suggests an $\mathrm{S}_{\mathrm{N}} 2$-like concerted displacement mechanism, in which the 
nucleofugal mobility of the halogen typically increases with its size. ${ }^{16-19}$ Conversely, the alternate associative addition/elimination route passing through a transient ate complex should markedly privilege the smaller elements chlorine and, in particular, fluorine ${ }^{20-23}$ due to the presence of a larger dipole between silicon and fluorine. As reviewed by Corriu, ${ }^{13 \mathrm{~b}}$ four- or sixcenter processes of the type $\mathrm{S}_{\mathrm{N}} \mathrm{i}(\mathrm{Si})$ are also unlikely, as (1) substitution of halotrialkylsilanes with allyllithiums proceed with inversion of configuration, thereby impeding on a cyclic transition state, and (2) increasingly polar solvents, which are expected to disrupt metal-halide interactions in a cyclic process, promote faster reactions and favour retention over inversion. Allylpotassiums are unlikely to behave differently.

Table 1. Condensation of pinenylpotassium with halotrialkylsilanes $\mathrm{XSiR}_{3}\left(\mathrm{R}=\mathrm{Me}\right.$ or $\left.{ }^{i} \mathrm{Pr}\right)$ : rates relative to the corresponding chlorotrialkylsilane (and, between parentheses, to chlorotriethylsilane $)$ in hexane $\left(k_{\mathrm{X} / \mathrm{Cl}}^{\mathrm{HEX}}\right)$ or in tetrahydrofuran $\left(k_{\mathrm{X} / \mathrm{Cl}}^{\mathrm{THF}}\right)$ at $-75^{\circ} \mathrm{C}$.

\begin{tabular}{clll}
\hline & $k_{\mathrm{X} / \mathrm{Cl}}^{\mathrm{HEX}}$ & $k_{\mathrm{X} / \mathrm{Cl}}^{\mathrm{THF}}$ & $\begin{array}{c}k_{\mathrm{X} / \mathrm{Cl}}^{\mathrm{THF}} \\
\mathrm{Me}\end{array}$ \\
$\mathrm{R}$ & $\mathrm{Me}$ & 1.0 & 0.25 \\
$\mathrm{~F}$ & 0.18 & $1.0(1.1)$ & 1.0 \\
$\mathrm{Cl}$ & $1.0(19)$ & 1.0 & 1.5 \\
$\mathrm{Br}$ & 2.7 & 0.79 & 2.0 \\
$\mathrm{I}$ & 4.4 & & \\
\hline
\end{tabular}

The leaving group effect surprisingly vanishes when pinenylpotassium are allowed to react with halotrimethylsilanes in tetrahydrofuran. Even more perplexing is the identical reactivity of small electrophiles from different families: the simultaneous exposure of pinenylpotassium to an excess of iodomethane and chlorotrimethylsilane afforded equal amounts of methylation and silylation products (i.e. their relative reaction rate constant is equal to 1.0). The same holds true for the competition between dimethyl sulfate and bis(trimethylsilyl) sulfate (see Scheme 2a). Albeit highly unusual, these results strongly hint at diffusion-controlled processes! ! $^{2-28}$

A final complication was encountered when pinenylpotassium was allowed to react with the mixed alkylation/silylation reagent methyl trimethylsilyl sulfate: the trimethylsilylated adduct was formed exclusively, with no trace of methyl attachment (Scheme 2b). This means one has to consider a two-stage scenario. First, the solvated organometallic substrate and the electrophilic reagent drift toward each other without experiencing any barrier, except perhaps an insignificant one when the solvation shell of the nucleophile opens to facilitate contact with the electrophile. Very favourable Coulombic attractions within the rearranged solvation shell then lead to irreversible pre-complexation, a mechanism reminiscent of gas phase chemistry. ${ }^{29}$ Within this cavity, dozens or even hundreds of collisions may occur until a product-relevant event, the ultimate carbon-carbon or carbon-silicon linking, occurs. In such an intramolecular competition, the organometallic species can thus select between the different electrophilic sites available in the mixed reagent. The more electropositive surface potential at the silicon attack site along the 
Si-O bond, compared to the opposite methyl group, is likely responsible for the regioselectivity (+ $31 \mathrm{vs.}+21 \mathrm{kcal} / \mathrm{mol}$; see experimental section for details). In the case of a diffusion-controlled intermolecular competition between two electrophiles, such as iodomethane and chlorotrimethylsilane (see Scheme 2a), the solvation shell surrounding the allylpotassium is as likely to rearrange around either electrophile. As this event is irreversible and Coulombic forces keep reacting species together until substitution, relative reaction rates close to unity are to be expected.

(a)

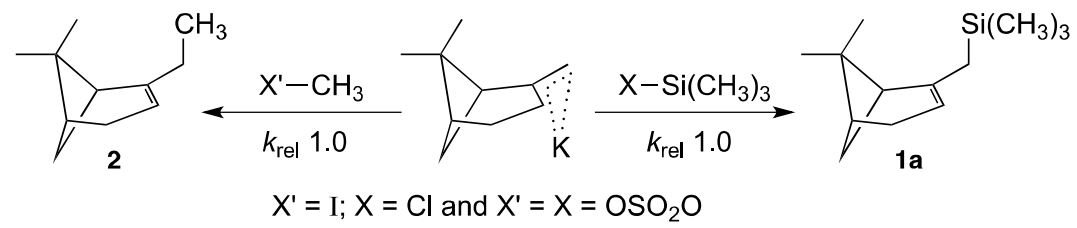

(b)

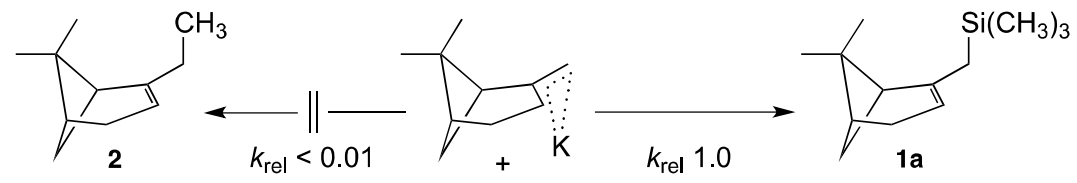

Scheme 2. Competitive electrophilic interceptions of pinenylpotassium (a) with the chlorotrimethylsilane/iodomethane and dimethyl sulfate/bis(trimethylsilyl) sulfate pairs of electrophiles, and (b) with methyl trimethylsilyl sulfate, intramolecularly.

\section{Conclusions}

We provided some support to an $\mathrm{S}_{\mathrm{N}} 2$-like mechanism for the substitution of pinenylpotassium with halotrialkylsilanes, as increasing reaction rates are determined along the fluoro-, chloro-, bromo- and iodotriisopropylsilane series in tetrahydrofuran, and along the analogous halotrimethylsilane series in hexane. However, all halotrimethylsilanes react at the same rate in tetrahydrofuran. Intermolecular competition experiments between different families of electrophiles, such as dimethyl sulfate and bis(trimethylsilyl) sulfate, also returned relative substitution rates near unity, while in an intramolecular competition, pinenylpotassium attacked exclusively the trimethylsilyl moiety of the mixed electrophile methyl trimethylsilyl sulfate. These results are consistent with a diffusion-controlled, irreversible precomplex formation between electrophiles and the allylmetal within a solvation shell, followed by substitution. To the best of our knowledge, diffusion-controlled reactions between organometallic reagents and electrophiles have never been reported. 


\section{Experimental Section}

General. For laboratory routine and abbreviations, see an earlier publication ${ }^{30}$ from the same authors. ${ }^{1} \mathrm{H}$ and $\left({ }^{1} \mathrm{H}\right.$-decoupled) ${ }^{13} \mathrm{C}$ NMR spectra were recorded at 400 and $101 \mathrm{MHz}$, respectively, all samples being dissolved in deuterochloroform. Fluorotrimethylsilane [bp 15-16 ${ }^{\circ} \mathrm{C}$ ] was condensed into a Schlenk tube plunged in a dry ice/toluene bath and stored at $-25{ }^{\circ} \mathrm{C}$. It was withdrawn from the Schlenk tube by means of a pipette briefly cooled with liquid nitrogen.

Fluorotriisopropylsilane. A solution of chlorotriisopropylsilane $(21 \mathrm{~mL}, 19 \mathrm{~g}, 0.10 \mathrm{~mol})$ in hexane $(0.10 \mathrm{~L})$ was heated to reflux in the presence of methanesulfonic acid $(6.5 \mathrm{~mL}, 9.6 \mathrm{~g}$, $0.10 \mathrm{~mol})$. After $20 \mathrm{~h}$, the solvent was stripped off and replaced by tetrahydrofuran $(0.10 \mathrm{~L})$. The mixture was heated to reflux for $20 \mathrm{~h}$ in the presence of spray-dried potassium fluoride $(5.8 \mathrm{~g}$, $0.10 \mathrm{~mol})$. Filtration, evaporation of the solvent and distillation afforded a colorless liquid; bp 27 $-28{ }^{\circ} \mathrm{C} / 2$ Torr (ref.: ${ }^{31}$ bp $\left.170{ }^{\circ} \mathrm{C}\right) ; n_{\mathrm{D}}^{20} 1.4191$ (ref.: $\left.{ }^{31} n_{\mathrm{D}}^{20} 1.4185\right)$; yield: $16 \mathrm{~g}(92 \%) .{ }^{1} \mathrm{H}$ NMR: $\delta$ 1.1 (m) ppm.

Bromotriisopropylsilane. Bromine $(1.3 \mathrm{~mL}, 4.0 \mathrm{~g}, 25 \mathrm{mmol})$ was added dropwise in the course of $5 \mathrm{~min}$ to a solution of triisopropylsilane $(5.1 \mathrm{~mL}, 4.0 \mathrm{~g}, 25 \mathrm{mmol})$ in hexane $(25 \mathrm{~mL})$ at $0{ }^{\circ} \mathrm{C}$. After the evaporation of the solvent, distillation afforded a colorless oil; bp $38-39^{\circ} \mathrm{C} / 1$ Torr; $n_{\mathrm{D}}^{20} 1.4735$; yield: $3.7 \mathrm{~g}(63 \%) .{ }^{1} \mathrm{H}$ NMR: $\delta 1.3(\mathrm{~m}, 3 \mathrm{H}), 1.1(\mathrm{~m}, 18 \mathrm{H}) \mathrm{ppm}$. ${ }^{13} \mathrm{C}$ NMR: $\delta$ 18.1, 14.2 ppm. $\mathrm{C}_{9} \mathrm{H}_{21} \mathrm{SiBr}$ (237.26): calcd. C 45.56, 8.92; found C 45.84, $\mathrm{H} 8.89$.

Iodotriisopropylsilane. A mixture of iodine $(6.3 \mathrm{~g}, 25 \mathrm{mmol})$ and triisopropylsilane $(5.1 \mathrm{~mL}$, $4.0 \mathrm{~g}, 25 \mathrm{mmol})$ in octane $(25 \mathrm{~mL})$ was heated to $125{ }^{\circ} \mathrm{C}$ for $45 \mathrm{~min}$. At $25{ }^{\circ} \mathrm{C}$, triphenylphosphine (approx. $0.3 \mathrm{~g}, 1 \mathrm{mmol}$ ) was added to the dark violet mixture, resulting in instantaneous discoloration. After the distillation of octane, a slightly pink liquid was collected; bp $69-71{ }^{\circ} \mathrm{C} / 1$ Torr (ref.: ${ }^{32}$ bp $82{ }^{\circ} \mathrm{C} / 2$ Torr); mp $16-17{ }^{\circ} \mathrm{C} ; n_{\mathrm{D}}^{20} 1.5073$; yield: $5.8 \mathrm{~g}(82 \%) .{ }^{1} \mathrm{H}$ NMR: $\delta 1.3(\mathrm{~m}, 3 \mathrm{H}), 1.1(\mathrm{~m}, 18 \mathrm{H}) \mathrm{ppm}$.

Bis(trimethylsilyl) sulfate. Chlorotrimethylsilane $(63 \mathrm{~mL}, 54 \mathrm{~g}, 0.50 \mathrm{~mol})$ in cyclohexane $(0.20$ L) was heated to reflux for $45 \mathrm{~min}$ in the presence of concentrated $(98 \%)$ sulfuric acid $(13 \mathrm{~mL}$, $24 \mathrm{~g}, 0.25 \mathrm{~mol})$, until the evolution of hydrogen chloride ceased. Distillation afforded a colorless oil that crystallized in square plates; mp $57-58{ }^{\circ} \mathrm{C}$ (ref.: ${ }^{33} \mathrm{mp} 57-58{ }^{\circ} \mathrm{C}$ ); yield: $95 \mathrm{~g}(78 \%) .{ }^{1} \mathrm{H}$ NMR: $\delta 0.41$ (s) ppm.

Methyl trimethylsilyl sulfate. Under vigorous stirring, anhydrous methanol $(10 \mathrm{~mL}, 8.0 \mathrm{~g}, 0.25$ mol) was added dropwise to the biphasic mixture of chlorosulfonic acid $(17 \mathrm{~mL}, 29 \mathrm{~g}, 0.25 \mathrm{~mol})$ and hexane $(0.10 \mathrm{~L})$. After $45 \mathrm{~min}$ at $25{ }^{\circ} \mathrm{C}$, the evolution of hydrogen chloride ceased. Chlorotrimethylsilane $(32 \mathrm{~mL}, 27 \mathrm{~g}, 0.25 \mathrm{~mol})$ was added all at once and the mixture was heated to reflux for $45 \mathrm{~min}$. Distillation afforded a colorless liquid; bp $45-47{ }^{\circ} \mathrm{C} / 1$ Torr (ref.: ${ }^{34}$ bp $93-$ $94{ }^{\circ} \mathrm{C} / 15$ Torr); $n_{\mathrm{D}}^{20} 1.4071$ (ref.: $\left.{ }^{34} n_{\mathrm{D}}^{20} 1.4065\right)$; yield: $36 \mathrm{~g}(79 \%) .{ }^{1} \mathrm{H}$ NMR: $\delta 3.94(\mathrm{~s}, 3 \mathrm{H})$, 0.44 (s, $9 \mathrm{H}$ ) ppm. ${ }^{13} \mathrm{C}$ NMR: $\delta$ 57.8, -0.1 ppm. $\mathrm{C}_{4} \mathrm{H}_{12} \mathrm{O}_{4} \mathrm{SSi}$ (184.29): calcd. C 26.07, H 6.56; found C 25.61, H 6.58 . 
Trimethyl(6,6-dimethylbicyclo[3.1.1]hept-2-en-2-ylmethyl)silane (1a). Butyllithium (50 $\mathrm{mmol})$ in hexane $(30 \mathrm{~mL})$ was added to a solution of potassium tert-butoxide $(5.6 \mathrm{~g}, 50 \mathrm{mmol})$ and (-)- $\beta$-pinene $(8.0 \mathrm{~mL}, 6.8 \mathrm{~g}, 50 \mathrm{mmol})$ in tetrahydrofuran $(50 \mathrm{~mL}) \mathrm{kept}$ in a dry ice/toluene bath. After $6 \mathrm{~h}$ at $-75^{\circ} \mathrm{C}$, chlorotrimethylsilane $(6.3 \mathrm{~mL}, 5.4 \mathrm{~g}, 50 \mathrm{mmol})$ was transferred into the bright orange mixture. The reaction mixture turned into a white suspension immediately after addition, and its temperature was raised to $25^{\circ} \mathrm{C}$. Water $(10 \mathrm{~mL})$ was then added and the suspension was filtered. After the evaporation of the solvents, distillation afforded a colorless liquid; bp $50-52{ }^{\circ} \mathrm{C} / 2$ Torr (ref.: ${ }^{35}$ bp $93{ }^{\circ} \mathrm{C} / 1$ Torr); $n_{\mathrm{D}}^{20} 1.4716$; yield: $9.1 \mathrm{~g}(87 \%) .{ }^{1} \mathrm{H}$ NMR: $\delta$ 5.01 (br. s, $1 \mathrm{H}$ ), dt $(2.35, J$ 8.3, $5.8 \mathrm{~Hz}, 1 \mathrm{H}$ ), 2.22 (symm. m, $2 \mathrm{H}$ ), 2.07 (symm. m, $1 \mathrm{H}$ ), 1.92 (t, $J 5.8 \mathrm{~Hz}, 1 \mathrm{H}), 1.54(\mathrm{~d}, J 14 \mathrm{~Hz}, 1 \mathrm{H}), 1.39(\mathrm{~d}, J 13 \mathrm{~Hz}, 1 \mathrm{H}), 1.27(\mathrm{~s}, 3 \mathrm{H}), 1.18(\mathrm{~d}, J 8.3 \mathrm{~Hz}, 1$ H), 0.89 (s, $3 \mathrm{H}), 0.00$ (s, $9 \mathrm{H}) \mathrm{ppm}$.

(6,6-Dimethyl-bicyclo[3.1.1]hept-2-en-2-ylmethyl)triethylsilane (1b). Analogously with chlorotriethylsilane $(8.5 \mathrm{~mL}, 7.5 \mathrm{~g}, 50 \mathrm{mmol})$ instead of chlorotrimethylsilane, distillation afforded the title compound as a colorless liquid; bp $84-86{ }^{\circ} \mathrm{C} / 2$ Torr; $n_{\mathrm{D}}^{20} 1.4856$; yield: $9.6 \mathrm{~g} \mathrm{(77 \% ).}{ }^{1} \mathrm{H}$ NMR: $\delta 5.02$ (symm. m, $1 \mathrm{H}$ ), 2.34 (dt, $J$ 8.3, $5.6 \mathrm{~Hz}, 1 \mathrm{H}$ ), 2.20 (symm. m, 2 H), 2.05 (symm. m, $1 \mathrm{H}), 1.89$ (td, J 5.6, $1.6 \mathrm{~Hz}, 1 \mathrm{H}), 1.57$ (dm, $J 14 \mathrm{~Hz}, 1 \mathrm{H}), 1.37$ (dm, $J 14$ $\mathrm{Hz}, 1 \mathrm{H}), 1.26(\mathrm{~s}, 3 \mathrm{H}), 1.17(\mathrm{~d}, J 8.3 \mathrm{~Hz}, 1 \mathrm{H}), 0.94(\mathrm{t}, J 7.8 \mathrm{~Hz}, 9 \mathrm{H}), 0.52(\mathrm{q}, J 8.0 \mathrm{~Hz}, 6 \mathrm{H})$ ppm. ${ }^{13} \mathrm{C}$ NMR: $\delta$ 145.7, 113.7, 48.1, 40.6, 37.8, 31.7, 31.4, 26.5, 23.4, 21.1, 7.4, 3.6 ppm. $\mathrm{C}_{16} \mathrm{H}_{30} \mathrm{Si}$ (250.50): calcd. C 76.72, H 12.07; found C 76.75, H 12.04.

(6,6-Dimethyl-bicyclo[3.1.1]hept-2-en-2-ylmethyl)triisopropylsilane (1c). Analogously with chlorotriisopropylsilane $(11 \mathrm{~mL}, 9.6 \mathrm{~g}, 50 \mathrm{mmol})$ instead of chlorotrimethylsilane, distillation afforded the title compound as a colorless oil; bp $110-112{ }^{\circ} \mathrm{C} / 1$ Torr; $n_{\mathrm{D}}^{20} 1.4968$; yield: $11 \mathrm{~g}$ (74\%). ${ }^{1} \mathrm{H}$ NMR: $\delta 5.10$ (symm. m, $1 \mathrm{H}$ ), 2.33 (dt, $J$ 8.3, $5.6 \mathrm{~Hz}, 1 \mathrm{H}$ ), 2.19 (symm. m, $2 \mathrm{H}$ ), 2.03 (symm. m, $1 \mathrm{H}), 1.96(\mathrm{td}, J$ 5.6, $1.3 \mathrm{~Hz}, 1 \mathrm{H}), 1.70(\mathrm{dm}, J 14 \mathrm{~Hz}, 1 \mathrm{H}), 1.34$ (dm, $J 14 \mathrm{~Hz}, 1 \mathrm{H})$, $1.26(\mathrm{~s}, 3 \mathrm{H}), 1.20(\mathrm{~d}, J 8.3 \mathrm{~Hz}, 1 \mathrm{H}), 1.0(\mathrm{~m}, 21 \mathrm{H}), 0.86(\mathrm{~s}, 3 \mathrm{H}) \mathrm{ppm} .{ }^{13} \mathrm{C}$ NMR: $\delta$ 145.6, 115.0, 48.5, 40.5, 37.9, 31.6, 31.5, 26.5, 20.9, 19.7, 18.9, 18.8, 11.5 ppm. $\mathrm{C}_{19} \mathrm{H}_{36} \mathrm{Si}$ (292.58): calcd. C 78.00, H 12.40; found C 77.93, H 12.21.

2-Ethyl-6,6-dimethylbicyclo[3.1.1]hept-2-ene (2). prepared analagously as described for silane 1a, with iodomethane $(3.1 \mathrm{~mL}, 7.1 \mathrm{~g}, 50 \mathrm{mmol})$ instead of chlorotrimethylsilane; colorless liquid; bp $55-56{ }^{\circ} \mathrm{C} / 20$ Torr (ref.: ${ }^{36}$ bp $35{ }^{\circ} \mathrm{C} / 2$ Torr); $n_{\mathrm{D}}^{20} 1.4693$ (ref.: ${ }^{36} n_{\mathrm{D}}^{20} 1.4705$ ); yield: $5.6 \mathrm{~g}$ (74\%). ${ }^{1} \mathrm{H}$ NMR: $\delta 5.16$ (symm. m, $1 \mathrm{H}$ ), 2.35 (dt, $J$ 8.3, $5.6 \mathrm{~Hz}, 1 \mathrm{H}$ ), 2.21 (symm. m, $2 \mathrm{H}$ ), 2.07 (symm. m, $1 \mathrm{H}), 2.0(\mathrm{~m}, 3 \mathrm{H}), 1.27(\mathrm{~s}, 3 \mathrm{H}), 1.15(\mathrm{~d}, J 8.5 \mathrm{~Hz}, 1 \mathrm{H}), 0.95$ (t, J 7.4 Hz, $3 \mathrm{H}), 0.82$ $(\mathrm{s}, 3 \mathrm{H}) \mathrm{ppm}$.

\section{Competition kinetics}

Four gas chromatography columns of different polarities were used to probe the concentrations of the substrates. We assume the relative rates $k_{\text {rel }}$ to be affected by an average error of $5 \%$ as long as the ratios do not exceed 10 , and $10 \%$ for higher rates. Relative rate constants were calculated using the standard formula for competition kinetics between two substrates A and B (see equation 1), where $k_{\text {rel }}$ is the relative rate constant, $[\mathrm{A}]_{0}$ and $[\mathrm{B}]_{0}$ are the initial 
concentrations of both substrates, and $[\mathrm{A}]_{t}$ and $[\mathrm{B}]_{t}$ are the concentrations after reaction with a substoichiometric amount of a reagent. ${ }^{37,38}$

$$
k_{\mathrm{rel}}=\frac{\ln \left([\mathrm{A}]_{t}\right)-\ln \left([\mathrm{A}]_{0}\right)}{\ln \left([\mathrm{B}]_{t}\right)-\ln \left([\mathrm{B}]_{0}\right)}
$$

\section{(a) Reactions of halotrimethylsilanes with pinenylpotassium in hexane}

Fluorotrimethylsilane $(0.23 \mathrm{~mL}, 0.18 \mathrm{~g}, 2.0 \mathrm{mmol})$, chlorotriethylsilane $(0.33 \mathrm{~mL}, 0.30 \mathrm{~g}, 2.0$ mmol) and nonane (approx. $0.2 \mathrm{~g}$ ), as an inert reference compound for quantification, were dissolved in hexane $(20 \mathrm{~mL}$ ). A sample (approx. $1.0 \mathrm{~mL}$ ) was withdrawn and treated with an excess of pinenylpotassium in tetrahydrofuran $(2.0 \mathrm{~mL}, 0.20 \mathrm{mmol})$ at $-75^{\circ} \mathrm{C}$ for $1 \mathrm{~min}$. After washing with brine $(5.0 \mathrm{~mL})$, the organic layer was analyzed by gas chromatography $[30 \mathrm{~m}, \mathrm{DB}-$ WAX, $70{ }^{\circ} \mathrm{C}, 3 \mathrm{~min}, 100{ }^{\circ} \mathrm{C}, 10 \mathrm{~min}, 40^{\circ} \mathrm{C} / \mathrm{min} ; 2 \mathrm{~m}, \mathrm{OV}-172 \%, 70{ }^{\circ} \mathrm{C}, 5 \mathrm{~min}, 150{ }^{\circ} \mathrm{C}, 10 \mathrm{~min}$, $40{ }^{\circ} \mathrm{C} / \mathrm{min}$ ]. The peak areas of trimethyl- and triethylsilylated products $\mathbf{1 a}$ and $\mathbf{1 b}$ relative to that of the standard, are considered to represent the initial amounts of fluorotrimethylsilane and chlorotriethylsilane in the reaction mixture (see Table 3). A fine suspension of pinenylpotassium in hexane, prepared from equimolar amounts of (-)- $\beta$-pinene $(0.32 \mathrm{~mL}, 0.27 \mathrm{~g}, 2.0 \mathrm{mmol})$, potassium tert-butoxide $(0.22 \mathrm{~g}, 2.0 \mathrm{mmol})$ and butyllithium $(2.0 \mathrm{mmol})$ in hexane $(20 \mathrm{~mL})$, was added to the solution of halotrialkylsilanes in the course of $15 \mathrm{~min}$ at $0{ }^{\circ} \mathrm{C}$, under vigorous stirring. A sample $(2.0 \mathrm{~mL})$ was withdrawn again, washed with brine $(10 \mathrm{~mL})$ and the organic layer was analyzed by gas chromatography to quantify the amounts of trimethyl- and triethylsilylated derivatives $\mathbf{1 a}$ and $\mathbf{1 b}$, and thus indirectly the amounts of unconsumed fluorotrimethylsilane and chlorotriethylsilane in the reaction mixture, followed by their relative rate constants $k_{\text {rel }}$ (Table 2). Unequal detector sensitivities for the allylsilanes were corrected by calibration factors. The experiment was repeated by replacing fluorotrimethylsilane with chlorotrimethylsilane $(0.26 \mathrm{~mL}, 0.22 \mathrm{~g}, 2.0 \mathrm{mmol})$. Chlorotriethylsilane $(3.3 \mathrm{~mL}, 3.0 \mathrm{~g}, 20$ mmol) was used in 10-fold excess when competing with bromotrimethylsilane $(0.26 \mathrm{~mL}, 0.31 \mathrm{~g}$, $2.0 \mathrm{mmol})$ and iodotrimethylsilane $(0.27 \mathrm{~mL}, 0.40 \mathrm{~g}, 2.0 \mathrm{mmol})$ for pinenylpotassium (2.0 mmol).

Table 2. Relative reaction rates $k_{\text {rel }}$ calculated from the amounts of halotrimethylsilanes X$\mathrm{Si}\left(\mathrm{CH}_{3}\right)_{3}$ and chlorotriethylsilane before ([A $]_{0}$ and $\left.[\mathrm{B}]_{0}\right)$ and after $\left([\mathrm{A}]_{t}\right.$ and $[\mathrm{B}]_{t}$ ) their competitive reaction with pinenylpotassium in hexane at $0{ }^{\circ} \mathrm{C}^{a}$

\begin{tabular}{lcccccl}
\hline $\mathrm{X}$ & {$[\mathrm{A}]_{0}$} & {$[\mathrm{~B}]_{0}$} & {$[\mathrm{~A}]_{t}$} & {$[\mathrm{~B}]_{t}$} & $k_{\mathrm{rel}}$ & $k_{\mathrm{X} / \mathrm{Cl}}^{\mathrm{HEX}} b$ \\
\hline $\mathrm{F}$ & 2.03 & 2.00 & 0.84 & 1.56 & 3.5 & 0.18 \\
$\mathrm{Cl}$ & 2.00 & 2.00 & 0.54 & 1.87 & 19 & 1.0 \\
$\mathrm{Br}$ & 2.02 & 20.0 & 0.65 & 19.56 & 51 & 2.7 \\
$\mathrm{I}$ & 1.98 & 20.0 & 0.53 & 19.69 & 84 & 4.4 \\
\hline
\end{tabular}


${ }^{a}[\mathrm{~A}]_{t}$ and $[\mathrm{B}]_{t}$ are indirectly determined by subtracting from the initial amounts $[\mathrm{A}]_{0}$ and $[\mathrm{B}]_{0}$ the amount of the products formed, trimethyl- and triethylsilylated derivatives $\mathbf{1 a}$ and $\mathbf{1 b} .{ }^{b}$ Rates relative to chlorotrimethylsilane.

\section{(b) Reactions of halotrimethylsilanes with pinenylpotassium in tetrahydrofuran}

Competition experiments in tetrahydrofuran (see Table 3) were performed analogously as described above, albeit at $-75{ }^{\circ} \mathrm{C}$ rather than at $0{ }^{\circ} \mathrm{C}$. The solution of pinenylpotassium in tetrahydrofuran $(20 \mathrm{~mL})$ at $-75^{\circ} \mathrm{C}$, prepared from equimolar amounts of $(-)$ - $\beta$-pinene $(0.32 \mathrm{~mL}$, $0.27 \mathrm{~g}, 2.0 \mathrm{mmol})$, potassium tert-butoxide $(0.22 \mathrm{~g}, 2.0 \mathrm{mmol})$ and butyllithium $(2.0 \mathrm{mmol}$; from a $1.60 \mathrm{M}$ solution in hexane, that was stripped of its solvent under high vacuum), was siphoned into the solution of halotrialkylsilanes in the course of $15 \mathrm{~min}$.

Table 3. Relative reaction rates $k_{\text {rel }}$ calculated from the amounts of halotrimethylsilanes $\mathrm{X}$ $\mathrm{Si}\left(\mathrm{CH}_{3}\right)_{3}$ and chlorotriethylsilane before ([A $]_{0}$ and $\left.[\mathrm{B}]_{0}\right)$ and after $\left([\mathrm{A}]_{t}\right.$ and $\left.[\mathrm{B}]_{t}\right)$ their competitive reaction with pinenylpotassium in tetrahydrofuran at $-75^{\circ} \mathrm{C}^{a}$

\begin{tabular}{lllllll}
\hline $\mathrm{X}$ & {$[\mathrm{A}]_{0}$} & {$[\mathrm{~B}]_{0}$} & {$[\mathrm{~A}]_{t}$} & {$[\mathrm{~B}]_{t}$} & $k_{\text {rel }}$ & $k_{\mathrm{X} / \mathrm{Cl}}^{\mathrm{THF}} b$ \\
\hline $\mathrm{F}$ & 2.08 & 2.00 & 1.10 & 1.12 & 1.1 & 1.0 \\
$\mathrm{Cl}$ & 2.00 & 2.00 & 1.06 & 1.13 & 1.1 & 1.0 \\
$\mathrm{Br}$ & 1.98 & 2.00 & 1.07 & 1.14 & 1.1 & 1.0 \\
$\mathrm{I}$ & 1.95 & 2.00 & 1.15 & 1.09 & 0.87 & 0.79 \\
\hline
\end{tabular}

${ }^{a, b}$ See Table 2 footnotes.

\section{(c) Reactions of halotriisopropylsilanes with pinenylpotassium in tetrahydrofuran}

Fluorotriisopropylsilane $(0.35 \mathrm{~g}, 2.0 \mathrm{mmol})$, chlorotriisopropylsilane $(0.39 \mathrm{~g}, 2.0 \mathrm{mmol})$ and nonane (approx. $0.13 \mathrm{~g}, 1.0 \mathrm{mmol}$ serving as an inert reference compound for quantification) were dissolved in tetrahydrofuran $(20 \mathrm{~mL})$. The concentrations of the halotriisopropylsilanes were evaluated by gas chromatography using two columns of different polarity [30 m, DB-1701, $70{ }^{\circ} \mathrm{C} ; 30 \mathrm{~m}$, NUKOL, $70{ }^{\circ} \mathrm{C}$ ] by comparing their peak areas to that of the internal standard nonane and by correcting the numbers thus found with separately determined calibration factors. A precooled solution of pinenylpotassium in tetrahydrofuran $(4.0 \mathrm{~mL})$, prepared from equimolar amounts of (-)- $\beta$-pinene $(0.32 \mathrm{~mL}, 0.27 \mathrm{~g}, 2.0 \mathrm{mmol})$, potassium tert-butoxide $(0.22 \mathrm{~g}, 2.0$ $\mathrm{mmol})$ and solvent-free butyllithium $(2.0 \mathrm{mmol}$; see section $\mathrm{b})$ was added to the reaction mixture at $-75{ }^{\circ} \mathrm{C}$. The mixture was stirred for $1 \mathrm{~min}$; a sample $(2.0 \mathrm{~mL})$ was then withdrawn, diluted with hexane $(20 \mathrm{~mL})$ and centrifuged. The clear organic layer was analyzed again by gas chromatography to determine the residual amounts of halotriisopropylsilanes (see Table 4). The experiment was repeated using bromotriisopropylsilane and iodotriisopropylsilane instead of fluorotriisopropylsilane. 
Table 4. Relative reaction rates $k_{\text {rel }}$ calculated with the amounts of halotriisopropylsilanes X$\mathrm{Si}\left({ }^{i} \mathrm{C}_{3} \mathrm{H}_{7}\right)_{3}$ and chlorotriisopropylsilane before $\left([\mathrm{A}]_{0}\right.$ and $\left.[\mathrm{B}]_{0}\right)$ and after $\left([\mathrm{A}]_{\mathrm{t}}\right.$ and $\left.[\mathrm{B}]_{\mathrm{t}}\right)$ their simultaneous reaction with pinenylpotassium in tetrahydrofuran at $-75{ }^{\circ} \mathrm{C}$

\begin{tabular}{llllll}
\hline $\mathrm{X}$ & {$[\mathrm{A}]_{0}$} & {$[\mathrm{~B}]_{0}$} & {$[\mathrm{~A}]_{\mathrm{t}}$} & {$[\mathrm{B}]_{\mathrm{t}}$} & $k_{\text {rel }}$ \\
\hline $\mathrm{F}$ & 2.03 & 2.01 & 1.54 & 0.68 & 0.25 \\
$\mathrm{Br}$ & 2.00 & 2.00 & 0.99 & 1.25 & 1.5 \\
$\mathrm{I}$ & 2.02 & 2.01 & 0.90 & 1.34 & 2.0 \\
\hline
\end{tabular}

\section{(d) Reactions of chlorotrimethylsilane and iodomethane with pinenylpotassium}

Chlorotrimethylsilane $(0.25 \mathrm{~mL}, 0.22 \mathrm{~g}, 2.0 \mathrm{mmol})$, iodomethane $(0.12 \mathrm{~mL}, 0.28 \mathrm{~g}, 2.0 \mathrm{mmol})$ and nonane (approx. $0.13 \mathrm{~g}, 1.0 \mathrm{mmol}$, serving as an inert reference compound for quantification) were dissolved in tetrahydrofuran $(20 \mathrm{~mL}$ ). Samples (approx. $1.0 \mathrm{~mL}$ ) were withdrawn and treated with an excess of pinenylpotassium in tetrahydrofuran $(2.0 \mathrm{~mL}, 2.0$ mmol) at $-75{ }^{\circ} \mathrm{C}$ for $1 \mathrm{~min}$. After washing with brine, the organic layer was analyzed by gas chromatography $\left[30 \mathrm{~m}\right.$, DB-1701, $70{ }^{\circ} \mathrm{C} ; 30 \mathrm{~m}$, NUKOL, $\left.70{ }^{\circ} \mathrm{C}\right]$. The peak areas of trimethylsilylated pinene 1a and 2-ethyl-8,9-dimethylbicyclo[3.3.1]hept-2-ene (2) relative to that of the standard were taken as equivalent to the initial amounts of chlorotrimethylsilane and iodomethane in the reaction mixture. Pinenylpotassium in tetrahydrofuran $(20 \mathrm{~mL})$, prepared from equimolar amounts of $(-)-\beta$-pinene $(0.32 \mathrm{~mL}, 0.27 \mathrm{~g}, 2.0 \mathrm{mmol})$, potassium tert-butoxide $(0.22 \mathrm{~g}, 2.0 \mathrm{mmol})$ and hexane-free butyllithium $(2.0 \mathrm{mmol}$; see section $\mathrm{b})$, was added to the reaction mixture in the course of $15 \mathrm{~min}$ at $-75^{\circ} \mathrm{C}$. A sample $(2.0 \mathrm{~mL})$ was withdrawn again, washed with brine $(10 \mathrm{~mL})$ and analyzed by gas chromatography to quantify the amounts of trimethylsilylated derivative 1a and methylated pinene $\mathbf{2}$ in order to calculate the amounts of unconsumed chlorotrimethylsilane and iodomethane in the reaction mixture.

\section{(e) Reaction of bis(trimethylsilyl) sulfate and dimethyl Sulfate with pinenylpotassium}

The experiment was performed analogously as described in the previous paragraph using bis(trimethylsilyl) sulfate $(0.48 \mathrm{~g}, 2.0 \mathrm{mmol})$ and dimethyl sulfate $(0.19 \mathrm{~mL}, 0.25 \mathrm{~g}, 2.0 \mathrm{mmol})$ instead of chlorotrimethylsilane and iodomethane.

\section{(f) Reaction of methyl trimethylsilyl sulfate with pinenylpotassium}

A solution of potassium tert-butoxide $(1.1 \mathrm{~g}, 10 \mathrm{mmol}),(-)-\beta$-pinene $(1.6 \mathrm{~mL}, 1.3 \mathrm{~g}, 10 \mathrm{mmol})$ and nonane $(1.0 \mathrm{~g})$ in tetrahydrofuran $(10 \mathrm{~mL})$ was added to hexane-free butyllithium $(10 \mathrm{mmol}$; see section b), and kept in a dry ice/toluene bath. After $6 \mathrm{~h}$ at $-75^{\circ} \mathrm{C}$, the reaction mixture was treated with methyl trimethylsilyl sulfate $(1.8 \mathrm{~g}, 10 \mathrm{mmol})$ in the course of $1 \mathrm{~min}$, and allowed to warm up to $25^{\circ} \mathrm{C}$. Water $(2.0 \mathrm{~mL})$ was then added and the suspension was filtered. The solution was analyzed by gas chromatography [30 m, DB-1701, $70{ }^{\circ} \mathrm{C} ; 30 \mathrm{~m}$, NUKOL, $\left.70{ }^{\circ} \mathrm{C}\right]$. Trimethylsilylated pinene 1a was obtained exclusively in $88 \%$ yield, as assessed by comparison with authentic samples. 


\section{Computational details}

The geometry of methyl trimethylsilyl sulfate was optimized with the TURBOMOLE 6.3.1 suite of programs (COSMOlogic GmbH \& Co. KG, D-51381 Leverkusen) with the TPSS-D3(BJ) functional ${ }^{39}$ and def2-TZVP basis sets. Convergence criteria were $10^{-6}$ Hartree and $10^{-3}$ atomic units as the maximum norm of the Cartesian gradient. The electrostatic potential map was superimposed on the isodensity surface of the structure with an isovalue of 0.002 , and was probed with a positive point charge along the $\mathrm{Si}-\mathrm{O}$ and $\mathrm{C}-\mathrm{O}$ bonds of the silyl and methyl electrophilic sites, respectively.

\section{Acknowledgements}

This work was supported by the Schweizerische Nationalfonds zur Förderung der wissenschaftlichen Forschung, Bern (grant 20-100'336-02). We also thank the Ohio Supercomputer Center (OSC) in Columbus for its generous allocation of computing time.

\section{References}

1. Mascal, M.; Hafezi, N.; Toney, M. D. J. Am. Chem. Soc. 2010, 132, 10662-10664. http://dx.doi.org/10.1021/ja103880c

2. Desponds, O.; Schlosser, M. J. Organomet. Chem. 1996, 507, 257-261. http://dx.doi.org/10.1016/0022-328X(95)05767-J

3. Schlosser, M.; Zellner, A.; Leroux, F. Synthesis 2001, 1830-1836. http://dx.doi.org/10.1055/s-2001-17521

4. Tochtermann, W. Angew. Chem. 1966, 78, 355-375; Angew. Chem., Int. Ed. Engl. 1966, 5, 351-371. http://dx.doi.org/10.1002/0470857250.ch9

5. Bassindale, A. R.; Glynn, S. J.; Taylor, P.G. In The Chemistry of Organic Silicon Compounds; Rappoport, Z.; Apeloig, Y. Eds.; Wiley: Chichester, 1998; Vol. 2, Part 1, pp 495-511.

http://dx.doi.org/10.1002/0470857250.ch9

6. de Keijzer, A. H. J. F.; de Kanter, F. J. J.; Schakel, M.; Osinga, V. P.; Klumpp, G. W. J. Organomet. Chem. 1997, 548, 29-32.

http://dx.doi.org/10.1016/S0022-328X(97)00166-6

7. Allen, A. D.; Modena, G. J. Chem. Soc. 1957, 3671-3678. http://dx.doi.org/10.1039/jr9570003671

8. Lickiss, P. D. In The Chemistry of Organic Silicon Compounds; Rappoport, Z.; Apeloig, Y. Eds.; Wiley: Chichester, 1998; Vol. 2, Part 1, pp 557-594. http://dx.doi.org/10.1002/0470857250.ch11 
9. Roark, D. N.; Sommer, L. H. J. Am. Chem. Soc. 1973, 95, 969-971. http://dx.doi.org/10.1021/ja00784a081

10. Vergnani, T.; Karpf, M.; Hoesch, L.; Dreiding, A. S. Helv. Chim. Acta 1975, 58, 2524 -2529. http://dx.doi.org/10.1002/hlca.19750580835

11. McKinnie, B. G.; Bhacca, N. S.; Cartledge, F. K.; Fayssoux, J. J. Org. Chem. 1976, 41, 1534-1539. http://dx.doi.org/10.1021/jo00871a009

12. Nguyen T. Anh.; Minot, C. J. Am. Chem. Soc. 1980, 102, 103-107.

13. (a) Corriu, R. J. P. ; Guerin, C. J. Organomet. Chem. 1980, 198, 231-320; (b) spec. p. 248 and $252-257$.

http://dx.doi.org/10.1016/S0022-328X(00)92857-2

14. Corriu, R. J. P. In The Chemistry of Organic Silicon Compounds; Patai, S.; Rappoport, Z. Eds.; Wiley: Chichester, 1989; Vol. 1, pp 305-370. http://dx.doi.org/10.1002/0470025107.ch4

15. Rauchschwalbe, G.; Schlosser, M. Helv. Chim. Acta 1975, 58, 1094-1099. http://dx.doi.org/10.1002/hlca.19750580413

16. Dhar, M. L.; Hughes, E. D.; Ingold, C. K.; Masterman, S. J. Chem. Soc. 1948, 2055-2057. http://dx.doi.org/10.1039/jr9480002055

17. Miller, W. T.; Bernstein, J. J. Am. Chem. Soc. 1948, 70, 3600-3604. http://dx.doi.org/10.1021/ja01191a016

18. Chapman, N. B.; Levy, J. L. J. Chem. Soc. 1952, 1673-1677.

19. Bartsch, R. A.; Bunnett, J. F. J. Am. Chem. Soc. 1968, 90, 408-417. http://dx.doi.org/10.1021/ja01004a036

20. Bevan, C. W. L. J. Chem. Soc. 1951, 2340-2342.

21. Bunnett, J. F.; Garbisch, E. W.; Pruitt, K. M. J. Am. Chem. Soc. 1957, 79, 385-391. http://dx.doi.org/10.1021/ja01559a040

22. Suhr, H. Chem. Ber. 1964, 97, 3277-3283. http://dx.doi.org/10.1002/cber.19640971204

23. Schlosser, M.; Rausis, T. Helv. Chim. Acta 2005, 88, 1240-1249. http://dx.doi.org/10.1002/hlca.200590104

24. Benson, S. W. The Foundations of Chemical Kinetics; McGraw-Hill: New York, 1960; spec. pp 494 and 542.

25. Caldin, E. F. Fast Reactions in Solution; Wiley: New York, 1964; spec. p 282.

26. Eigen, M.; Eyring, E. M. J. Am. Chem. Soc. 1962, 84, 3254-3256. http://dx.doi.org/10.1021/ja00876a008

27. Halpern, J. J. Chem. Educ. 1968, 45, 372-380. http://dx.doi.org/10.1021/ed045p372

28. Laidler, K. J. Chemical Kinetics, 3rd Edn.; HarperCollinsPublishers: New York, 1987; spec. p 221. 
29. DePuy, C. H. J. Org. Chem. 2002, 67, 2393-2401.

http://dx.doi.org/10.1021/jo0163593

30. Masson, E.; Schlosser, M. Eur. J. Org. Chem. 2005, 4401-4405.

http://dx.doi.org/10.1002/ejoc.200500390

31. Eaborn, C. J. Chem. Soc. 1953, 494-501.

32. Weidenbruch, M.; Peter, W. J. Organomet. Chem. 1975, 84, 151-163. http://dx.doi.org/10.1016/S0022-328X(00)90028-7

33. Sommer, L. H.; Pietrusza, E. W.; Kerr, G. T.; Whitmore, F. C. J. Am. Chem. Soc. 1946, 68, 156-156.

http://dx.doi.org/10.1021/ja01205a523

34. Duffaut, N. ; Calas, R. ; Dunoguès, J. Bull. Soc. Chim. Fr. 1963, 512-517.

35. Andrianome, M.; Delmond, B. Tetrahedron Lett. 1985, 26, 6341-6342. http://dx.doi.org/10.1016/S0040-4039(01)84593-7

36. Schulze, K.; Beutmann, K.; Habermann, A. K.; Himmelreich, U. J. Prakt. Chem. 1993, 335, 445-448.

http://dx.doi.org/10.1002/prac.19933350509

37. Ingold, C. K.; Shaw, F. R. J. Chem. Soc. 1927, 2918 - 2929.

http://dx.doi.org/10.1039/jr9270002918

38. Schlosser, M.; Ladenberger, V. Chem. Ber. 1967, 100, 3901 - 3915. http://dx.doi.org/10.1002/cber.19671001211

39. (a) Tao, J.; Perdew, J. P.; Staroverov, V. N.; Scuseria, G. E. Phys. Rev. Lett. 2003, 91, 146401-146404 http://dx.doi.org/10.1103/PhysRevLett.91.146401

(b) Grimme, S.; Antony, J.; Ehrlich, S.; Krieg, H. J. Chem. Phys. 2010, 132, 154104154119;

(c) Grimme, S.; Ehrlich, S.; Goerigk, L. J. Comput. Chem. 2011, 32, 1456-1465.

http://dx.doi.org/10.1002/jcc.21759 